\title{
Relações lineares entre incidência e severidade foliar em patossistema multiplo de manchas foliares em arroz irrigado
}

\author{
Luiz Carlos Bordin ${ }^{1 *}$, Ricardo Trezzi Casa ${ }^{2}$, Leandro Luiz Marcuzzo ${ }^{3}$, Clovis Arruda Souza ${ }^{2}$, André Gheller ${ }^{4}$, Rômulo \\ Luís Zancan ${ }^{4}$, Juan Carlo Stoltz ${ }^{4}$
}

${ }^{1}$ Instituto Federal Catarinense - IFC/Campus Camboriú, CEP 88.340-000, Camboriú, SC, e-mail: luizcarlosbordin@hotmail.com; ${ }^{2}$ Centro de Ciências Agroveterinárias - CAV/UDESC, CEP 88520-000, Lages, SC, Bolsista de Produtividade em Pesquisa do CNPq, e-mail: a2rtc@cav.udesc. br; souza_clovis@cav.udesc.br; ${ }^{3}$ Instituto Federal Catarinense - IFC/Campus Rio do Sul, CP 441, CEP 89163-356, Rio do Sul, SC: ; ${ }^{4}$ Aluno de graduação do curso de Agronomia do Centro de Ciências Agroveterinárias - CAV/UDESC. Bolsista de Iniciação Científica - PIBIC/CNPq, e-mail: andreh_gheller@hotmail.com; romulo.zancan@hotmail.com; juan.stoltz@hotmail.com. *Parte modificada da tese de doutorado do primeiro autor. Universidade do Estado de Santa Catarina, 2013.

Autor para correspondência: Leandro Luiz Marcuzzo (marcuzzo@ifc-riodosul.edu.br)

Data de chegada: 03/03/2015. Aceito para publicação em: 19/02/2016.

$10.1590 / 0100-5405 / 2081$

\section{RESUMO}

Bordin, L.C.; Casa, R.T.; Marcuzzo, L.L.; Souza, C.A.; Gheller, A.; Zancan, R.L.; Stoltz, J.C. Relações lineares entre incidência e severidade foliar em patossistema múltiplo de manchas foliares em arroz irrigado. Summa Phytopathologica, v.42, n.3, p.239-242, 2016.

A ocorrência de doenças foliares na cultura do arroz irrigado pode reduzir o rendimento e comprometer a qualidade do grão. O objetivo do trabalho foi avaliar a relação entre incidência e severidade na intensidade de manchas foliares em arroz irrigado. Os experimentos foram conduzidos com o cultivar SCS 116 Satoru nas safras 2011/12 e 2012/13, no município de Rio do Oeste, Alto Vale do Itajaí, estado de Santa Catarina. O delineamento foi de blocos casualizados, com quatro repetições e seis tratamentos constituídos de aplicações de mistura de fungicidas triazol (difenoconazole) e estrobilurina (azoxistrobina), sendo uma aplicação em final de perfilhamento (V8), duas aplicações (V8 + R0, iniciação da panícula), três aplicações (V8 + R0 + R2, emborrachamento), quatro aplicações (V8 + R0 + R2 + R4, floração), cinco aplicações (V8 + R0 + R2 + R4 + R6, grão leitoso) com objetivo de gerar um gradiente de intensidade de doença. Antes de cada aplicação foi determinada a incidência e a severidade das doenças foliares. Nas duas safras as doenças foliares predominantes foram brusone, mancha parda e escaldadura. Os dados obtidos foram submetidos à análise de regressão. Utilizando a equação com melhor ajuste nas duas safras e substituindo o valor de severidade de $1 \%$ obtém-se incidência de 30,$80 ; 35,86 ; 25,91 ; 30,26$; 32,90 respectivamente nos estádios fenológicos de perfilhamento, iniciação da panícula, emborrachamento, floração e grão leitoso. A severidade estimada com base na incidência e vice-versa possibilita seu uso pela assistência técnica no monitoramento das manchas foliares na cultura do arroz irrigado.

Palavras-chave: Oryza sativa, manchas foliares, intensidade de doença.

\section{ABSTRACT}

Bordin, L.C.; Casa, R.T.; Marcuzzo, L.L.; Souza, C.A.; Gheller, A.; Zancan, R.L.; Stoltz, J.C. Linear relationships between leaf incidence and severity in multiple pathossystem of leaf spots in irrigated rice. Summa Phytopathologica, v.42, n.3, p.239-242, 2016.

The occurrence of leaf diseases in irrigated rice can reduce yield and grain quality. The aim of this study was to evaluate the relationship between incidence and severity in the intensity of leaf spots in irrigated rice. Experiments were conducted with the rice cultivar SCS 116 Satoru in 2011/12 and 2012/13 growing seasons in Rio do Oeste, located in Alto Vale do Itajaí, Santa Catarina State, Brazil. The design was in randomized blocks with four replicates and six treatments consisting of applications of a mixture of the fungicides triazole (difenoconazole) and strobilurin (azoxystrobin), which included one application at the end of tillering (V8), two applications (V8 + R0, panicle initiation), three applications (V8 + R0 + R2, booting), four applications (V8 + R0 + R2 + R4, flowering), five applications ( $\mathrm{V} 8+\mathrm{R} 0+\mathrm{R} 2+\mathrm{R} 4+\mathrm{R} 6$, milky grain), with the objective to create a disease intensity gradient. Before each application, the incidence and the severity of leaf diseases were determined. In both growing seasons, the predominant leaf diseases were blast, brown spot and scald. The obtained data were subjected to regression analysis. Using the equation that best fit in both crop seasons and substituting the severity value for $1 \%$, the incidences of $30.80 ; 35.86 ; 25.91 ; 30.26 ; 32.90$ were obtained at the phenological stages of tillering, panicle initiation, booting, flowering and milky grain, respectively. The disease severity estimated based on the incidence and vice-versa allows its use for technical assistance in the monitoring of leaf spots in irrigated rice.

Keywords: Oryza sativa, leaf spots, disease intensity.

O arroz (Oryza sativa L.) cultivado e consumido em todos os continentes é caracterizado como principal alimento para mais da metade da população mundial, destacando-se, principalmente, em países em desenvolvimento, nos quais, desempenha função estratégica nos âmbitos econômico e social (23).

A área semeada com arroz irrigado na safra 2012/13 no estado de Santa Catarina foi de aproximadamente 150 mil hectares, com produtividade média de $6.828 \mathrm{~kg} \mathrm{ha}^{-1}(8)$. Porém, esta produtividade ainda está abaixo da alcançada em lavouras que adotam alto nível tecnológico e do potencial produtivo de áreas experimentais que é de 10 a 12 toneladas ha ${ }^{-1}(7,14)$.

Dentre os fatores limitantes de expressão do potencial produtivo desta cultura encontram-se as doenças fúngicas foliares que diminuem a área foliar útil das plantas de arroz e, consequentemente, a capacidade da 
planta de realizar fotossíntese e produzir fotoassimilados, influenciando no enchimento de grãos em plantas infectadas (4). Segundo Balardin \& Borin (3), tais doenças são responsáveis por danos variáveis entre 20 e $50 \%$ na produtividade.

Dentre as principais doenças fúngicas foliares nas regiões produtoras de arroz irrigado no estado do Rio Grande do Sul e Santa Catarina destacam-se a brusone [Pyricularia grisea (Cooke) Saccardo], mancha parda [Bipolaris oryzae (Breda de Hann) Shoemaker] e escaldadura [Gerlachia oryzae (Hashioka \& Yokogi) W. Gams] $(6,17)$.

A baixa disponibilidade de material genético resistente ao complexo de doenças foliares (20) e o uso intensificado das áreas de cultivo proporcionaram aumento na ocorrência e nos danos causados por doenças fúngicas na orizicultura mundial (18).

Um dos critérios técnicos que justifica a aplicação de fungicidas tem como base o monitoramento da intensidade da doença que pode ser expresso pela incidência e/ou severidade foliar, ou seja, o percentual de folhas sintomáticas ou a porcentagem da área da folha afetada pelos sintomas, respectivamente, no caso das manchas foliares $(5,19)$.

A determinação da severidade foliar é mais trabalhosa, porém é a que melhor expressa a intensidade de manchas foliares. Sua determinação com mais alta acurácia pode ser feita por estimativas visuais da severidade, com o auxílio de escalas diagramáticas ou por medição das lesões por análise de imagem em computador (5, 19). Devido à maior subjetividade nas estimativas e necessidade de treinamento ou uso contínuo de uma escala diagramática, o critério da severidade tem sido pouco usado pela assistência técnica, comparado ao da incidência cuja mensuração é mais simples, rápida e objetiva.

Diante do exposto, o presente trabalho teve por objetivo avaliar as relações entre a incidência e severidade e obter equações preditivas da severidade da mancha foliar a partir de mensurações de incidência e severidade em patossistema múltiplo no cultivar de arroz irrigado SCS 116 Saturu, em diferentes estádios fenológicos da cultura.

\section{MATERIAL E MÉTODOS}

Os experimentos foram instalados nas safras agrícolas de 2011/12 (semeadura em 03/10/2011 e colheita em 23/03/2012) e 2012/13 (semeadura em 17/09/2012 e colheita em 13/3/2013), nos mesmos ambientes, em lavouras comerciais, no município de Rio do Oeste, Alto Vale do Itajaí, estado de Santa Catarina.

As temperaturas médias durante a condução dos experimentos foram de $21,8{ }^{\circ} \mathrm{C}$ e $21,3{ }^{\circ} \mathrm{C}$ e as precipitações, $594 \mathrm{~mm}$ e $755 \mathrm{~mm}$, respectivamente, para as safras 2011/12 e 2012/13 (10).

Na semeadura foi utilizado o cultivar SCS 116 Satoru, cujas características são ciclo tardio (de 136 a 159 dias da semeadura à maturação), medianamente resistente à brusone e sem informação para as demais doenças foliares (mancha parda e escaldadura). A semeadura foi realizada no sistema pré-germinado na densidade de $150 \mathrm{~kg} \mathrm{ha}^{-1}$. As adubações de base, a aplicação de adubação nitrogenada, bem como o controle de plantas invasoras e pragas foram realizadas de acordo com as recomendações técnicas para a cultura do arroz no sul do país (16).

Os experimentos foram conduzidos em delineamento de blocos casualizados com quatro repetições. Nas safras 2011/12 e 2012/13 foram realizados seis tratamentos constituídos de número de aplicações de mistura comercial de fungicidas (difenoconazol) e estrobilurina (azoxistrobina) $\left(0,2+0,4 \mathrm{~L} \mathrm{ha}^{-1}\right.$ p.c.), mais óleo mineral (Nimbus) $(0,5$ $\mathrm{L} \mathrm{ha}^{-1}$ p.c.), dose indicada pelo fabricante, totalizando 24 parcelas, sendo um dos tratamentos (testemunha) sem aplicação de fungicida. A área correspondente a cada parcela foi de 5,0 x 2,5 metros.
Os fungicidas foram aplicados em intervalos de 15 a 20 dias pelo uso de pulverizador costal de pressão constante gerado por gás $\mathrm{CO}_{2}$, com volume de calda de 200 litros ha ${ }^{-1}$.

As aplicações de fungicidas ocorreram nos estádios de perfilhamento (V8), iniciação da panícula (R0), emborrachamento (R2), floração (R4) e grão leitoso (R6), de acordo com a escala de Counce et al. (9), sendo uma aplicação (V8), duas aplicações (V8 + R0), três aplicações (V8 + $\mathrm{R} 0+\mathrm{R} 2)$, quatro aplicações (V8 + R0 + R2 + R4) e cinco aplicações $(\mathrm{V} 8+\mathrm{R} 0+\mathrm{R} 2+\mathrm{R} 4+\mathrm{R} 6)$, com o objetivo de gerar gradiente de intensidade de doença conforme metodologia proposta por Sah \& Mackenzie (15), para determinar em qual severidade é correspondente a incidência e vice-versa.

A coleta das folhas para avaliação da incidência e severidade da brusone, mancha parda e escaldadura foi realizada antes de cada aplicação de fungicida, destacando-se três folhas expandidas, do extrato inferior, mediano e superior, em dez plantas ao acaso de cada parcela experimental. Duas pessoas treinadas quantificaram a severidade om auxílio de escala diagramática para brusone (2), mancha parda (13) e escaldadura (11).

Os dados obtidos foram submetidos a análise de regressão pelo programa estatístico Microsoft Office Excel versão 2007, a fim de obter equações preditivas da severidade em função da incidência para avaliações em cada estádio de desenvolvimento da cultura e em cada safra agrícola.

\section{RESULTADOS E DISCUSSÃO}

Nas duas safras agrícolas foram obtidas equações com probabilidade estatística significativa, permitindo relacionar as variáveis testadas nos cinco estádios de desenvolvimento da cultura (Figura 1). Em todos os momentos avaliados e em ambas as safras, os coeficientes angulares foram significativos, resultados demonstrados pela inclinação da reta, o que possibilita relacionar a incidência e a severidade foliar do patossistema múltiplo de manchas foliares em arroz irrigado. Ao analisar os coeficientes de determinação, observa-se que os menores valores ocorreram na safra 2011/12, o que pode ser atribuído à menor severidade da doença, pois a baixa severidade dificulta obter boa acuracidade e precisão na mensuração das doenças, uma vez que as lesões iniciais são pequenas e variáveis em forma, cor e presença ou não de tecido clorótico.

Os dados foram melhor ajustados pela severidade $=-0,218+0,047 \mathrm{I}$ $\left(\mathrm{R}^{2}=0,833\right)$ na fase de emborrachamento ( $\left.R 2\right)$ na safra $2011 / 12$ e na safra 2012/13 na fase de grão leitoso (R6) expresso pela severidade = $-1,369+0,072 \mathrm{I}\left(\mathrm{R}^{2}=0,871\right)$ (Figura 1$)$. Nos estádios iniciais, o grau de relação entre a incidência e a severidade foliar tendeu a ser menor, em função de que a ocorrência da doença se deu praticamente sobre todas as folhas da planta, enquanto a severidade ainda era muito variável.

Utilizando a equação com melhor ajuste nas duas safras $(\mathrm{y}=$ $\left.-1,369+0,072 \mathrm{I}, \mathrm{R}^{2}=0,871\right)$ e fazendo uma simulação utilizando valor arbitrário de $1 \%$ de severidade na planta obtém-se incidência de 30,80; 35,$86 ; 25,91 ; 30,26 ; 32,90$, respectivamente, nos estádios fenológicos de perfilhamento (V8), iniciação da panícula (R0), emborrachamento (R2), floração (R4) e grão leitoso (R6).

Nas fases iniciais de uma epidemia de manchas foliares a incidência e a severidade aumentam até que todas as folhas sejam infectadas, a partir desse ponto, o aumento da intensidade da doença pode ocorrer somente pela severidade (12). A incidência é útil para avaliar doenças quando a epidemia encontra-se em sua fase inicial podendo, nesse caso, ser correlacionada com a severidade (1). 


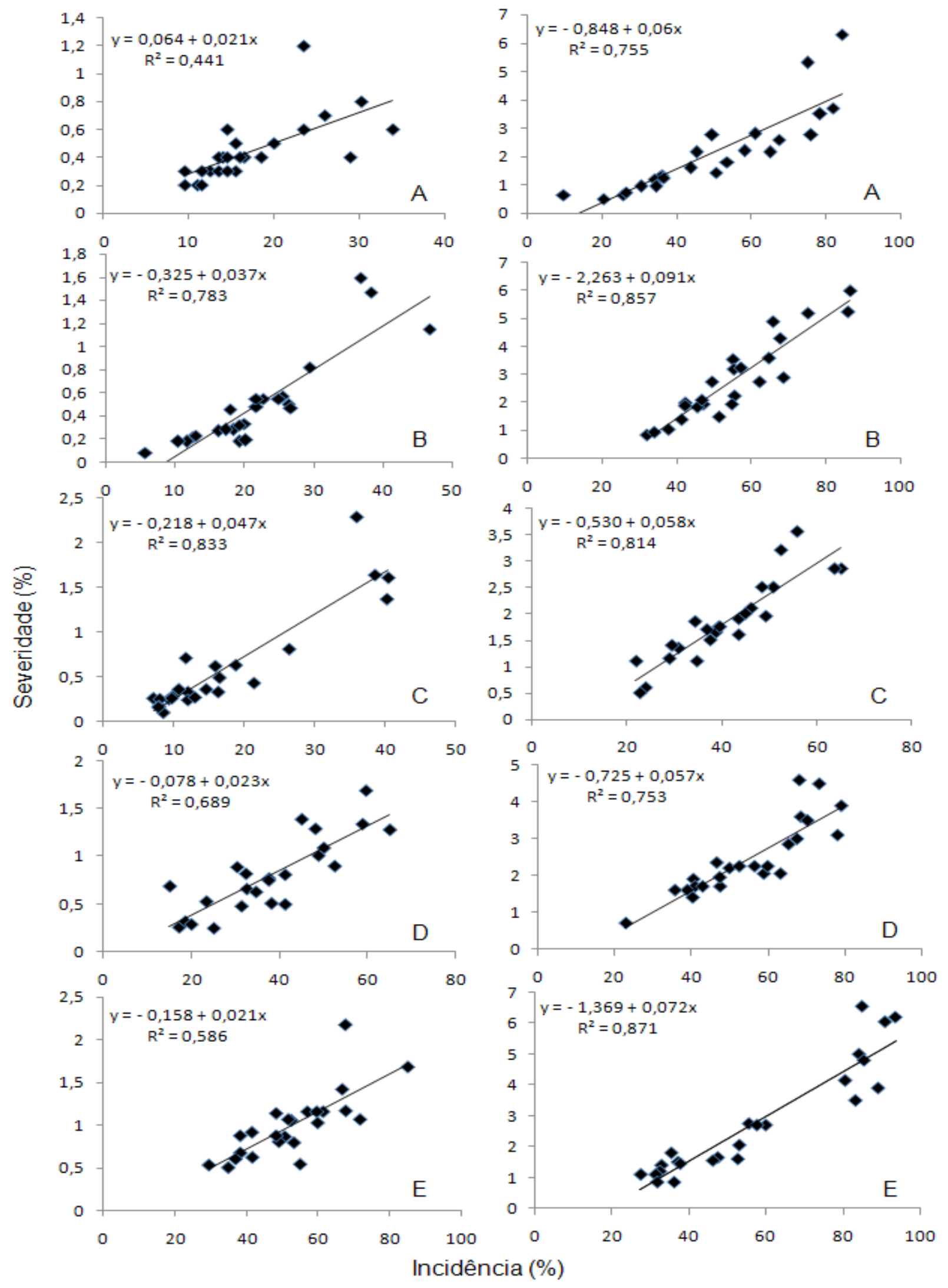

Figura 1. Relação entre a incidência e a severidade foliar de patossitema múltiplo em arroz irrigado, cultivar SCS 116 Satoru no perfilhamento (A), iniciação da panícula (B), emborrachamento (C), floração (D) e grão leitoso (E) nas safras 2011/12 e 2012/13 em Rio do Oeste, SC. 
O uso da incidência como ferramenta substituta na avaliação da severidade facilita o uso pela assistência técnica no monitoramento das manchas foliares do arroz irrigado em diferentes estádios de desenvolvimento da cultura.

\section{REFERÊNCIAS}

1. Amorim, L. Avaliação de doenças. In: Bergamim Filho, A.; Kimati, H.; Amorim, L. (Ed.). Manual de fitopatologia. 3. ed. São Paulo: Ceres, 1995. v. 1, cap. 31, p.234-235

2. Azevedo, L.A.S. Manual de quantificação de doenças de plantas. São Paulo: Novartis Biociências, 1997. 11 p.

3. Balardin, R.S.; Borin, R.C. Doenças na cultura do arroz irrigado. Santa Maria: UFSM, 2001. 48p.

4. Bedendo, I.P. Doenças do arroz. In: Kimati, H.; Amorim, L. Manual de fitopatologia. São Paulo: Agronômica Ceres, 1997. cap. 10, p. 85-99.

5. Bergamin Filho, A.; Amorim, L. Doenças de plantas tropicais: epidemiologia e controle econômico. São Paulo: Ceres,1996. 289p.

6. Bordin, L. Equações de funções de dano de doenças foliares e sua relação com o rendimento e a qualidade de grãos em arroz irrigado. 2013. 135f. Tese (Doutorado em produção vegetal) - Universidade do Estado de Santa Catarina, Lages.

7. Bordin, L.C.; Casa, R.T.; Gheller, A.; Marcuzzo, L.L.; Fontana Junior, F.; Colla Junior, G. Influência do número de aplicações de fungicidas sobre o rendimento dos cultivares de arroz irrigado Epagri 109 e SCS 116 Satoru no Alto Vale do Itajaí/SC. In: Congresso Brasileiro de Arroz Irrigado, 7., 2011, Balneário Camboriú. Anais...Itajaí : Epagri 2011. v.1, p. 547-550.

8. Companhia Nacional de Abastecimento. Acompanhamento de safra brasileira: grãos, $9^{\circ}$ levantamento, Brasília, 2013.

9. Counce, P.; Keisling, T. C.; Mitchell, A. J. A uniform, objective, and adaptive system for expressing rice development. Crop Science, Madison, v.40, n.2, p.436-443, 2000.

10. Epagri. Atlas climatológico do estado de Santa Catarina. Florianópolis: Disponivel em: $<$ http://ciram.epagri.sc.gov.br/portal >. Acesso em: 20 nov. 2013.

11. International Rice Research Institute. Standard evaluation system for rice. $4^{\text {nd }}$ ed. Manila: IRRI, 1996. $52 \mathrm{p}$.

12. James, W.C.; Shih, C.S. Relationship between incidence and severity of powdery mildew and leaf rust on witer wheat. Phytopathology, St. Paul, v.63, p.183-187, 1973.

13. Lenz, G.; Balardin, R.S.; Dala Corte, G.; Marques, L.N.; Debona, D. Escala diagramática para avaliação de severidade de mancha-parda em arroz. Ciência Rural, Santa Maria, v.40, n.4, p.752-758, 2010.

14. Mariot, C.H.P.; Silva, P.R.F.; Menezes, V.G.; Teichmann, L.L. Resposł ta de duas cultivares de arroz irrigado à densidade de semeadura e à adubação nitrogenada. Pesquisa Agropecuária Brasileira, Brasília, DF, v. 38, n. 2, p. 233-241, 2003.

15. Sah, D.N.; Mackenzie, D.R. Methods of generating different levels of disease epidemics in loss experiments. In: Teng, P.S. (Ed). Crop loss assessement and pest management. St Paul. MN: Americam phytopathological Society, p.90-95, 1987.

16. Sosbai. Arroz Irrigado: recomendações técnicas da pesquisa para o Sul do Brasil. In: Reunião Técnica da Cultura do Arroz Irrigado, 29., 2012, Itajaí. Anais...Itajaí: Sociedade Sul-Brasileira de Arroz Irrigado, 2012. 179p.

17. Teló, G.M.; Marchezan, E.; Ferreira, R.B.; Menezes, N.L.; Hansel, D.S.S.; Sartori, G.M.S. Aplicação de fungicida em plantas de arroz irrigado e seu efeito na qualidade de sementes durante o armazenamento. Revista Brasileira de Sementes, Londrina, v. 34, n.1, 2012.

18. Vale, F.X.R.; Jesus Junior, W.C.; Zambolim, L. Epidemiologia aplicada ao manejo de doenças de plantas. Belo Horizonte: Perffil, 2004. 531p.

19. Walter, M.; Marchezan, E.; Ávila, L.A. Arroz: composição e características nutricionais. Ciência Rural, Santa Maria, v.38, n.4, p.11841192, 2008. 